\title{
A AUTOPOIESE NO DIREITO E O FUNCIONALISMO SISTÊMICO DE GÜNTHER JAKOBS NA APLICAÇÃO DA LEI PENAL
}

\author{
AUTOPOIESIS IN LAW AND GÜNTHER JAKOBS'S SYSTEMIC FUNCTIONALISM IN \\ CRIMINAL LAW ENFORCEMENT
}

\section{Daniela Portugal*}

Sumário: Introdução. 1. A autopoiese no direito. 1.1. Sobre o paradigma autopoiético. 1.2. O direito autopoiético. 2. O direito penal e o funcionalismo. 2.1. O funcionalismo teleológico de Claus Roxin. 2.2. O funcionalismo sistêmico de Günther Jakobs. 3. O funcionalismo sistêmico e a aplicação da lei penal. 3.1. A teoria da imputação objetiva e a noção de "risco" no direito penal. 3.2. Os tipos penais de perigo abstrato e a proteção da norma penal. Considerações finais. Referências.

Resumo: O presente artigo tem por objetivo a promoção de uma reflexão crítica acerca da compreensão do direito como um sistema autopoiético, enfocando-se, especialmente, a aplicação da lei penal. Assim, serão estudados dois modelos penais funcionalistas antagônicos, de modo a verificar qual deles melhor resolve os problemas modernos relativos à aplicação da lei penal, destacando-se a imputação objetiva da norma penal e aceitação dos tipos penais de perigo abstrato.

Palavras-Chave: Autopoiese; Funcionalismo; Lei Penal; Imputação; Risco.

\footnotetext{
${ }^{*}$ Universidade Federal da Bahia.
} 
Abstract: This article aims to promote a critical reflection about the understanding of law as an autopoietic system, focusing, in particular, the application of criminal law. Thus, two opposing functionalists currents in criminal law will be studied, in order to see which one best solves modern problems related to the application of criminal law, highlighting the objective imputation of criminal legal norm and the acceptance of criminal types of abstract danger.

Keywords: Autopoiesis; Functionalism; Criminal Law; Imputation; Risk.

\section{INTRODUÇÃO}

O presente artigo tem por objetivo investigar se o modelo de sistema autopoiético pode ser aplicado ao estudo do direito e, mais especificamente, quais impactos esta forma de estudo acarreta para a aplicação de normas penais.

Assim, no primeiro tópico, será feito um estudo sobre as características do sistema autopoiético, investigando-se se o pensamento sistemático pode ser aplicado a ciências sociais e, sobretudo, ao direito. Primeiramente, será analisado o paradigma autopoiético, a sua autoorganização e sua forma de relação paradoxalmente autônoma e dependente em relação ao entorno.

Posteriormente, analisa-se o direito como um sistema autopoiético, quando serão avaliados os elementos responsáveis por diferenciar o sistema jurídico do entorno social que o circunda. Passa-se, em seguida, a examinar se o direito possui um sistema operacional fechado capaz de viabilizar o seu estudo como sendo um sistema autopoiético.

No tópico seguinte de desenvolvimento, serão expostas duas importantes correntes finalistas do direito penal - o funcionalismo teleológico e o funcionalismo sistêmico, como forma de avaliar o impacto da teoria dos sistemas no direito penal. Para tanto, as duas mencionadas correntes, absolutamente antagônicas, serão apresentadas para que se examine, mais adiante, qual delas serve melhor à aplicação da lei penal. 
No último capítulo, serão estudados a teoria da imputação objetiva e os tipos penais de perigo abstrato, cujo tratamento possui respostas distintas a depender do modelo funcionalista que se adote, para que se examine qual das correntes se adapta melhor à realidade do direito penal.

Ao final, avalia-se qual modelo sistemático melhor se adapta ao estudo do direito penal - a autopoiese ou a alopoiese -, repercutindo, por consequência, na corrente funcionalista que deve prevalecer para fins de aplicação da lei penal - o funcionalismo sistêmico ou o funcionalismo teleológico.

\section{A AUTOPOIESE NO DIREITO}

Nas seguintes linhas, tratar-se-á da (im)possibilidade de aplicação da teoria dos sistemas ao direito, utilizando como base principal a concepção de sistema autopoiético desenvolvida por Niklas Luhmann. Serão expostas as principais caracterísicas do sistema autopoiético e, em seguida, será feita uma análise sobre a forma como as características são reproduzidas no sistema jurídico.

\subsection{Sobre o Paradigma Autopoiético}

Niklas Luhmann desenvolve a sua teoria dos sistemas a partir da influência de modelos sistemáticos nos diversos campos do saber entre o final da década de 50 e o início da década de 60, tais como a cibernética, ciências cognitivas, teoria da comunicação, teoria da evolução, dentre outras teorias ${ }^{1}$.

Luhmann busca superar a tradicional contraposição entre ciências naturais e ciências do espírito, é dizer, entre hard sciences e humanities por intermédio da identificação das características com base nas quais estas ciências se diferenciam do meio em que são formadas ${ }^{2}$.

\footnotetext{
${ }^{1}$ LUHMANN, Niklas. La sociedad de la sociedad. México: Universidad Iberoamericana Biblioteca Francisco Xavier Clavigero, 2006, p. 40.

${ }^{2}$ Id. Ibid. p. 40-44.
} 
Nesse sentido, o autor entende a sociedade como um sistema complexo. Para tanto, explica o surgimento do sistema a partir da diferenciação deste em relação ao seu entorno. Esclarece que a dependência e a independência são características que coexistem na relação entre o sistema e o meio ${ }^{3}$. A dependência deriva do fato de o sistema emergir do meio, entretanto, o sistema adquire independência em razão do seu desenvolvimento, pautado na inclusão de relações autorreferenciais, produzindo uma espécie de auto-organização ${ }^{4}$.

Significa dizer que a formação de um sistema surge do meio que lhe cerca e deste se destaca ao adquirir autonomia. Deste modo, o sistema depende do meio sem, todavia, estar determinado por ele, uma vez que constitui a sua própria forma de organização ${ }^{5}$.

Neste sentido, Luhmann desenvolve o conceito de autopoiese, explicando, inicialmente, não se tratar da produção sistemática de um determinado modelo, mas da capacidade de produção de uma diferenciação entre o sistema e o seu entorno ${ }^{6}$. Assim, quando o sistema destaca-se do seu entorno, ele ganha um espaço interno de liberdade, o que corresponderia à produção de uma "indeterminação interna"7.

Significa dizer que o surgimento do sistema é marcado, em um primeiro momento, por um processo de diferenciação - quando o sistema destaca-se do todo - e, em seguida, pela construção de um espaço de indeterminação - quando o interior do sistema se mostra livre para ser auto-organizado, rompendo-se, com isso, a tradicional dicotomia entre sistemas abertos e sistemas fechados para tratar de um sistema complexo.

O espaço indeterminado do interior do sistema é, gradativamente, preenchido por estruturas próprias e sentidos comunicativos peculiares, de modo que o sistema social tem como característica a produção do seu próprio modelo de comunicação ${ }^{8}$.

Em sentido semelhante, de acordo com Leonel Severo Rocha, o sistema autopoiético supera um paradoxo entre o passado e o futuro, entre o aberto e o fechado. Isto porque sistema autopoiético emerge do meio - de onde se extrai sua origem e parcela de dependência com o passado - e, simultaneamente, destaca-se desse entorno ao se diferenciar, criando um

\footnotetext{
${ }^{3}$ LUHMANN, Niklas. La sociedad de la sociedad. México: Universidad Iberoamericana Biblioteca Francisco Xavier Clavigero, 2006, p. 44.

${ }^{4}$ Id. Ibid. p. 45.

${ }^{5}$ Id. Ibid. loc. cit.

${ }^{6}$ Id. Ibid. p. 45.

${ }^{7}$ Id. Ibid. p. 46.

${ }^{8}$ Id. Ibid. loc. cit.
} 
modelo próprio de organização - que irá pautar a relação do sistema com o futuro, condicionando relações que sequer foram firmadas 9 .

Trata-se, portanto, de uma forma de atuação voltada para o passado em sua origem, mas também voltada para o futuro em razão da construção de uma auto-organização. O sistema autopoiético é também fechado e aberto porque se, por um lado, emerge do entorno e com ele se relaciona durante seu processo evolutivo ${ }^{10}$; por outro, diferencia-se do meio, criando estruturas próprias de comunicação, fora das quais não é possível travar relações previsíveis ${ }^{11}$.

É possível perceber, portanto, que a concepção autopoiética de Luhmann não se confunde com a elaboração de um modelo sistemático fechado, uma vez que admite relações externas entre o sistema e o entorno - relações estas, porém, que são travadas de forma inespecífica, já que a previsibillidade da forma e da organização só se mostra possível dentro de uma estrutura sistemática ${ }^{12}$.

A especificação de relações pressupõe, portanto, a autonomia entre o sistema e o meio processo que Luhmann chama de diferenciação ${ }^{13}$. A mencionada autonomia, por sua vez, está presente tanto no âmbito estrutural quanto na esfera operacional, do que se extrai o conceito de autopoiese como sendo a possibilidade de construção de operações próprias, garantindo, inclusive, a previsibilidade de operações futuras ${ }^{14}$.

Ao definir a sociedade como um sistema complexo, Luhmann especifica tratar-se de um sistema capaz de abranger todos os demais sistemas sociais, resgatando, em um sentido aproximativo, a noção de "Política" desenvolvida por Aristóteles, em que este se refere à possibilidade de uma comunidade conter outras ${ }^{15}$. Note-se que, em ambos os casos, é estabelecida uma relação sistema/entorno, base em que é construída a teoria geral dos sistemas ${ }^{16}$.

\footnotetext{
${ }^{9}$ ROCHA, Leonel Severo; SCHWARTZ, Germano; CLAM, Jean. Introdução à teoria do sistema autopoiético de direito. Porto Alegre: Livraria do Advogado, 2005, p. 38.

${ }^{10}$ Segundo o autor, "um sistema fechado é impossível, não pode haver um sistema que se auto-reproduza somente nele mesmo". De outro lado, "se falamos em sistema aberto, já nem falamos mais em sistema, podemos falar de outra coisa". Op. cit. p. 38.

${ }^{11}$ LUHMANN, Niklas. La sociedad de la sociedad. México: Universidad Iberoamericana Biblioteca Francisco Xavier Clavigero, 2006, p. 39.

${ }^{12}$ Id. Ibid. p. 46

${ }^{13}$ Id. Ibid. p. 46.

${ }^{14}$ Id. Ibid. p. 46.

${ }^{15}$ Id. Ibid. p. 55

${ }^{16}$ Id. Ibid. loc. cit.
} 
É importante perceber, ainda, que, quando um sistema passa a conter outros sistemas que dele se diferenciam, o próprio sistema abrangente é, a um só tempo, sistema e entorno, a depender do ponto de vida de observação ${ }^{17}$. Por tal razão que Luhmann explica que o processo de diferenciação não corresponde a uma decomposição do todo em partes, especialmente porque cada sistema parcial, de certo modo, reproduz o sistema total, só que com uma diferenciação própria ${ }^{18}$.

Após definir a sociedade como um sistema, Luhmann passa para uma análise no plano dos sistemas autopoiéticos, caracterizados, como já se viu, por serem autorreferenciais e operacionalmente fechados ${ }^{19}$. Explica, nesse sentido, que a comunicação é a base operacional de uma sociedade, acrescentando que, dentre os diversos meios de comunicação, tais como escrita, imprensa e meios eletrônicos, a linguagem é o meio comunicativo que mais se destaca $^{20}$.

A clausura operacional deve-se ao fato de não ser possível estabelecer, em uma operação própria do sistema, um contato com o entorno, além da impossibilidade de outros sistemas, também situados no entorno, interferirem em processos autopoiéticos de um sistema operacionalmente fechado $^{21}$. Significa que um mesmo meio pode dar origem a mais de um sistema e, sendo estes sistemas autopoiéticos, a operação de um não interfere no funcionamento do outro: todos coexistem mantendo, em si, sua autonomia.

A mencionada clausura operacional, por sua vez, conduz à auto-organização do sistema, já que suas estruturas não podem ser construídas ou transformadas senão por meio de operações próprias do sistema ${ }^{22}$. É por esta razão que a "linguagem só pode se modificar com a comunicação, e não de forma imediata como o fogo"23. Deste modo, a sociedade é um sistema comunicativamente fechado, pois a comunicação só pode ser produzida por meio da própria comunicação, sendo a linguagem o meio essencial de comunicação, responsável por garantir a regular e contínua autopoiese de toda a sociedade ${ }^{24}$.

\footnotetext{
${ }^{17}$ LUHMANN, Niklas. La sociedad de la sociedad. México: Universidad Iberoamericana Biblioteca Francisco Xavier Clavigero, 2006, p. 471.

${ }^{18}$ Id. Ibid. p. 473.

${ }^{19}$ Id. Ibid. p. 56.

${ }^{20}$ Id. Ibid. loc. cit.

${ }^{21}$ Id. Ibid. p. 66.

${ }^{22}$ Id. Ibid. p. 67.

${ }^{23}$ Id. Ibid. loc. cit. Tradução livre.

${ }^{24}$ Id. Ibid., passim.
} 


\subsection{O Direito Autopoiético}

De acordo com Leonel Severo Rocha, Luhmann supera a analítica de Kelsen e a hermenêutica de Hart ao desenvolver a concepção de direito como um sistema autopoiético, cuja função é a de exigir "a realização de graduações que possibilitem expectativas comportamentais recíprocas e que são orientadas a partir de expectativas sobre tais expectativas". ${ }^{25}$

Significa dizer que a diferenciação do direito (sistema parcial) em face do entorno social (sistema total) tem por principal objetivo garantir uma estabilização das relações por meio da produção de expectativas, criando uma organização própria, que difere, por exemplo, do modelo de organização pautado nas noções de moralidade e de pecado.

José Galindo Monteagudo, ao apresentar a obra "Die Gesellschaft der Gesellschaft", de Luhmann, destaca que as ações humanas, em si, são desprovidas de sentido, necessitando que um observador a (re)construa como um fato significativo. Esta atribuição de significado pode se operar tanto por meio de um sistema psíquico quanto por meio de um sistema social ${ }^{26}$.

Monteagudo exemplifica relatando o caso de uma testemunha que observa um autor sair correndo de uma casa e especula ter ocorrido um roubo: esta atribuição de sentido pode estar inserida em um sistema psíquico (caso o observador guarde para si a significação) ou em um sistema social (caso ele comunique à polícia a sua especulação) ${ }^{27}$. Na hipótese de haver comunicação do fato às autoridades públicas, a hipótese do roubo é um fenômeno social já tratado por um sistema social funcionalmente especializado - o direito ${ }^{28}$.

Deste modo, um dos grandes méritos da teoria luhmanniana está em superar a mera observação de atores e avançar para o estudo das comunicações que são travadas entre os atores sociais, ocasião em que o direito passa a figurar um meio capaz de viabilizar a estabilização das relações.

\footnotetext{
${ }^{25}$ ROCHA, Leonel Severo; SCHWARTZ, Germano; CLAM, Jean. Introdução à teoria do sistema autopoiético de direito. Porto Alegre: Livraria do Advogado, 2005, p. 31.

${ }^{26}$ LUHMANN, Niklas. La sociedad de la sociedad. México: Universidad Iberoamericana Biblioteca Francisco Xavier Clavigero, 2006, p. XXXI.

${ }^{27}$ Id. Ibid. loc. cit.

${ }^{28}$ Id. Ibid. p. XXXI.
} 
É neste sentido que Niklas Luhmann, na obra "Das Recht der Gesellschaft" afirma a clausura operacional do direito ${ }^{29}$. De acordo com o autor, deve-se mudar o foco de atenção hoje voltado para a busca pela legitimação do direito positivo, ou mesmo para a distinção entre este e o direito natural - para a análise da insuficiência do conceito de positividade ${ }^{30}$.

Não se pode entender por sistema jurídico um simples conjunto de regras, mas como um conjunto de operações fáticas dispostas sobre a forma de comunicações, de modo que o ponto de partida para a análise do direito não deve ser a norma ou uma tipologia de valores, mas a já referida distinção entre sistema e entorno ${ }^{31}$.

O direito atuaria, conforme explica Luhmann em "Sociologia do Direito I", entre a complexidade e a contingência de experiências, produzindo expectativas sociais ${ }^{32}$. Isto porque, para cada experiência humana, há uma infinidade de possibilidades (complexidade) e, dentre estas possibilidades, existem aquelas que não são esperadas (contingência) ${ }^{33}$.

Assim, explica o autor, resumidamente, que "complexidade significa seleção forçada, e contingência significa perigo de desapontamento e necessidade de assumir-se riscos" ${ }^{34}$. É a partir desta relação em que são construídas estruturas estabilizadas que visam a impedir os mencionados desapontamentos ${ }^{35}$.

Em "Sociologia do Direito II", o autor acrescenta que o processo de normatização deve estar acompanhado na organização das suas formas de imposição, de modo que estará tão mais organizado quanto maior for a suposição de que, uma vez transgredida a norma, será imposta a consequência jurídica, pautando-se o sistema jurídico, pois, na previsibilidade ${ }^{36}$.

Desse modo, a autopoiese corresponderia a uma nova forma de estudo de antigos problemas, tais como a relação entre a estrutura posta e o processo; entre a norma e a

\footnotetext{
${ }^{29}$ LUHMANN, Niklas. El Derecho de la Sociedad. Formatação eletrônica de João Protásio Farias Domingues de Vargas, Marjorie Corrêa Marona e Juliana Neuenschwander Magalhaes. Brasil, 2002, passim.

${ }^{30}$ Id. Ibid. p. 24.

${ }^{31}$ Id. Ibid. loc. cit.

${ }^{32}$ LUHMANN, Niklas. Sociologia do Direito I. Coleção dirigida por Eduardo Portella. Trad. Gustavo Bayer. Série Biblioteca Tempo Universitário n 75/Série Estudos Alemães. Rio de Janeiro: Tempo Brasileiro, 1983, p. 45.

${ }^{33}$ Id. Ibid. loc. cit.

${ }^{34}$ Id. Ibid. p. 46.

35 Id. Ibid. p. 47.

${ }^{36}$ LUHMANN, Niklas. Sociologia do Direito II. Coleção dirigida por Eduardo Portella. Trad. Gustavo Bayer. Série Biblioteca Tempo Universitário n 75/Série Estudos Alemães. Rio de Janeiro: Tempo Brasileiro, 1985, p. 20 .
} 
decisão ${ }^{37}$, pois não mais se questiona o tipo de estrutura que se deve aceitar (problema da legitimação do direito), mas sim se as relações travadas obedecem aos critérios de reconhecimento estabelecidos no próprio sistema jurídico.

Nesse mesmo sentido, Jean Clam explica que o direito autopoiético produz os critérios que irão conformar sua autodefinição, tais como "unidade", "autonomia", dentre outros critérios, de modo que a positividade passa a ser insuficiente para explicar o sistema jurídico $^{38}$.

O autor ainda trata da lógica de autoprodução do direito, pautada no "reconhecimento dos processos de geração do direito a partir do direito" ${ }^{39}$. É a partir desse processo que o direito evolui e se auto-reproduz ${ }^{40}$.

Marcelo Neves critica a compreensão luhmanniana de direito como um sistema autopoiético, advertindo a impossibilidade deste modelo de estudo ser transposto à modernidade periférica, referindo-se, especialmente, à realidade brasileira, em razão da sobreposição de interesses particulares às operações reconhecidas pelo sistema jurídico ${ }^{41}$.

A partir de tal visão, Neves subverte a tese de Luhmann ao dizer que não será o sistema jurídico que irá conformar as relações privadas futuramente traçadas, mas o interesse particular que irá se sobrepor ao próprio direito, conformando-o, impossibilitando, assim, a construção de uma identidade no sistema jurídico ${ }^{42}$.

Por tal razão, Neves sustenta que, em vez de autopoiese, caberia tratar do direito como um sistema alopoiético ${ }^{43}$. Isto significa, segundo o autor, que não há "uma esfera de juridicidade apta a, de acordo com seus próprios critérios e de forma congruentemente generalizada, reciclar as influências advindas do seu contexto econômico e político"44.

\footnotetext{
${ }^{37}$ LUHMANN, Niklas. El Derecho de la Sociedad. Formatação eletrônica de João Protásio Farias Domingues de Vargas, Marjorie Corrêa Marona e Juliana Neuenschwander Magalhaes. Brasil, 2002, p. 24.

${ }^{38}$ ROCHA, Leonel Severo; SCHWARTZ, Germano; CLAM, Jean. Introdução à teoria do sistema autopoiético de direito. Porto Alegre: Livraria do Advogado, 2005, p. 113.

${ }^{39}$ Id. Ibid. loc. cit.

${ }^{40}$ Id. Ibid. loc. cit.

${ }^{41}$ NEVES, Marcelo. Luhmann, Habermas e o estado de direito. Lua Nova: Revista de Cultura e Política, n. 37, São Paulo, 1996. Disponível em: http://www.scielo.br/scielo.php?pid=S010264451996000100006\&script=sci_arttext. Acesso em: 03 de abril de 2013.

${ }^{42}$ Id. Ibid.

${ }^{43}$ Id. Ibid.

${ }^{44}$ Id. Ibid.
} 
Deste modo, o problema não está na falta de abertura cognitiva, mas no "insuficiente fechamento operacional (autorreferência)" ${ }^{45}$, que se apresenta como um obstáculo à identidade do sistema jurídico. Por consequência, também não se pode esperar por uma generalização das expectativas sociais a partir dos textos legais, inviabilizando, reflexamente, a própria distinção entre o lícito e o ilícito "seja por falta de institucionalização (consenso) ou de identificação do sentido das normas"46.

De acordo com Marcelo Neves, não há como negar a autonomia do direito, mas também não se pode acreditar no ideal ilusório de estabilização e de autorreferência dada a evidente sobreposição "de poder e dinheiro ao direito" ${ }^{47}$.

Já Benedito Hespanha, de forma mais moderada, atenta para o fato de a concepção de um sistema autopoiético de direito depender, necessariamente, da Constituição como fonte reguladora e produtora, mas portadora de uma função real de criação, e não de simples valor simbólico ${ }^{48}$.

Com isso, muito embora não se possa afirmar a inexistência de uma influência de condicionantes sociais e políticas do meio na produção do direito, as ações e decisões produzidas em um sistema jurídico autopoiético devem ser autoproduzidas a partir de um sistema constitucional substancial ${ }^{49}$.

Em sentido semelhante, Germano Schwartz esclarece que a Constituição surge, precisamente, a partir da diferenciação funcional entre o jurídico e o político, apresentando-se como uma "aquisição evolutiva da sociedade, pois substitui o direito natural pelo direito da razão, tornando-os operacionalizáveis" ${ }^{50}$.

No tópico seguinte, serão analisadas duas perspectivas funcionalistas distintas acerca do direito penal, sendo uma delas de orientação sistêmica, como forma de avaliar se este modelo,

\footnotetext{
${ }^{45}$ NEVES, Marcelo. Luhmann, Habermas e o estado de direito. Lua Nova: Revista de Cultura e Política, n. 37, São Paulo, 1996. Disponível em: http://www.scielo.br/scielo.php?pid=S010264451996000100006\&script=sci_arttext. Acessado em: 03 de abril de 2013.

${ }^{46}$ Id. Ibid.

${ }^{47}$ Id. Ibid.

${ }^{48}$ HESPANHA, Benedito. A autopoiese na construção do jurídico e do político de um sistema constitucional. Revista dos Tribunais - Cadernos de Direito constitucional e Ciência Política. São Paulo, Ano 7, n. 27, abriljunho de 1999, p. 62.

${ }^{49}$ Id. Ibid. p. 62.

50 SCHWARTZ, Germano. Autopoiese e constituição: os limites da hierarquia e as possibilidades da circularidade. Revista Brasileira de Direito Constitucional (RBDC): Revista do Programa de Pós-Graduação Lato Sensu em Direito Constitucional. Escola Superior de Direito Constitucional (ESDC). São Paulo, n.6, 2005, p. 215.
} 
aplicado ao direito penal, concretiza um ideal de segurança jurídica e de estabilização social ou se, ao revés, torna a aplicação da lei penal insegura e instável.

O presente estudo, portanto, propõe-se a transitar entre estas duas percepções distintas acerca do direito, como forma de avaliar se o direito penal, mais especificamente, existe em razão de um fim ou para cumprir uma determinada missão, resgatando o problema da legitimação na aplicação da lei ao fato.

\section{O DIREITO PENAL E O FUNCIONALISMO}

A doutrina penal apresenta uma série de correntes funcionalistas que, em comum, possuem o fato de buscarem atribuir ao direito penal uma função específica, divergindo, por sua vez, sobre qual seria esta função. Por questões de delimitação temática, o presente estudo não se ocupará senão do estudo das correntes funcionalistas sustentadas por Claus Roxin e por Günther Jakobs, não chegando a tratar de outras concepções não menos importantes, tais como o funcionalismo reducionista de Eugenio Raúl Zaffaroni ${ }^{51}$ e o funcionalismo do controle social de Hassemer ${ }^{52}$.

\subsection{O Funcionalismo Teleológico de Claus Roxin}

Ensina Luís Greco que o funcionalismo teleológico propõe uma revisão de toda a teoria do delito a fim de que esta seja (re)compreendida à luz da política criminal, permitindo que decisões valorativas sejam introduzidas no sistema do direito penal ${ }^{53}$.

Explica o autor que o funcionalismo teleológico possui como base metodológica a jurisprudência dos valores (Wertungsjurisprudenz), segundo a qual "construções jurídicas devem ser conscientemente guiadas por determinados valores e finalidades" 54 . A jurisprudência dos valores, nesse sentido, teria superado o modelo neokantista, o qual,

\footnotetext{
${ }^{51}$ Cf. ZAFFARONI, Eugenio Raul; ALAGIA, Alejandro; SLOKAR, Alejandro. Derecho penal: parte general. Buenos Aires: Ediar, 2001.

${ }^{52}$ Cf. HASSEMER, Winfried. Perspectivas de uma moderna política criminal. Revista Brasileira de Ciências Criminais. São Paulo, n. 8, out-dez, 1994, p. 41-51.

${ }^{53}$ GRECO, Luís. A teoria da imputação objetiva: uma introdução. In: ROXIN, Claus. Funcionalismo e imputação objetiva no direito penal. Trad. Luís Greco. Rio de Janeiro/ São Paulo: Renovar, 2002, p. 62.

${ }^{54}$ Id. Ibid. p. 63.
} 
malgrado tenha referido a importância dos valores para o direito, não chegou a lhes atribuir uma posição teleológica objetivamente válida ${ }^{55}$.

É nesse sentido que Claus Roxin utiliza-se da política criminal do Estado Social e Democrático de Direito para restringir a esfera de atuação do direito penal, atribuindo-se a função de tutela subsidiária de bens jurídicos, impondo, inclusive, limites de atuação para o intérprete e o legislador, superando a tradicional concepção segundo a qual somente o legislador trabalha com política criminal ${ }^{56}$.

De acordo com Roxin, desde, aproximadamente, 1970, tem sido buscado o desenvolvimento de um sistema "jurídico-penal teleológico-racional ou funcional" 57 , buscando-se superar, definitivamente, o modelo científico-natural ou lógico de causalidade por um conjunto de regras orientadas a uma valoração jurídica - projeto que se iniciou com o neokantismo, na década de 30, mas acabou por ficar esquecido em razão da Segunda Guerra Mundial $^{58}$.

Nesse sentido, como esclarece Raquel Lima Scalcon, o estudo do pensamento sistemático foi fundamental para que a Escola de Munique construísse a teoria funcionalista do direito penal, estruturando o sistema de forma teleológica, utilizando valores como o pondo de partida para um redimensionamento de tradicionais elementos da teoria do delito ${ }^{59}$.

Assim, conforme esclarecem Alice Bianchini, Antonio García-Pablos de Molina e Luiz Flávio Gomes, de acordo com essa corrente funcionalista, a intervenção do direito penal somente se legitima quando estiver a cumprir a função de proteção de um bem jurídico ${ }^{60}$. $\mathrm{O}$ bem jurídico, seja ele material ou imaterial, corresponde a um interesse social juridicamente tutelado, o qual, em razão de sua relevância e da insuficiência de proteção por parte de outros ramos do direito, ganha, no direito penal, uma proteção substancial.

\footnotetext{
55 GRECO, Luís. A teoria da imputação objetiva: uma introdução. In: ROXIN, Claus. Funcionalismo e imputação objetiva no direito penal. Trad. Luís Greco. Rio de Janeiro/ São Paulo: Renovar, 2002, p. 63.

${ }^{56}$ Id. Ibd. p. 64-65.

${ }^{57}$ ROXIN, Claus. Funcionalismo e imputação objetiva no direito penal. Trad. Luís Greco. Rio de Janeiro/São Paulo: Renovar, 2002, p. 205.

${ }^{58}$ Id. Ibd. 206-207.

${ }^{59}$ SCALCON, Rachel Lima. Funcionalismo penal da Escola de Munique: contributos e inconsistências de uma construção do conceito de crime a partir dos fins de política criminal. Revista Síntese Direito Penal e Direito Processual Penal. Continuação da Revista IOB de Direito Penal e Processual Penal. Porto Alegre, v.1, n.1, abr./maio, 2000, p. 80-81.

${ }^{60}$ BIANCHINI, Alice; MOLINA, Antonio García-Pablos; GOMES, Luiz Flávio. Direito Penal: introdução e princípios fundamentais. 2. ed. São Paulo: Revista dos Tribunais, 2009, p. 232-235.
} 
A proteção desempenhada por parte do direito penal, todavia, somente se justifica quando excepcional (princípio da intervenção mínima), uma vez que a sanção penal é, de todas as dispostas no direito, a mais drástica, em razão de atingir, como regra geral, o direito fundamental de liberdade.

É, também, por esta razão que a seleção dos bens jurídicos que irão compor a esfera jurídico-penal de tutela é feita com base na observância dos princípios da fragmentariedade e da subsidiariedade ${ }^{61}$. Em razão do primeiro, entende-se que a justiça penal não se aplica à tutela de todo e qualquer bem, mas tão somente daqueles mais preciosos para o ordenamento jurídico, tais como a vida; dignidade sexual; liberdade; integridade física, dentre outros.

Já o princípio da subsidiariedade afirma o direito penal como ultima ratio, isto é, última esfera de proteção, de modo que a criminalização de uma conduta só se legitima quando se verificar que as consequências jurídicas previstas por outros ramos do direito como forma de coibir a lesão ao bem não são suficientes para impor o desestímulo à prática criminosa.

De acordo com Roxin, portanto, a lesão a um bem jurídico é pressuposto de punibilidade, afastando-se do direito penal as meras imoralidades, as contravenções, ideologias, arbitrariedades, dentre outras situações em que não se apresente um risco jurídico substancialmente relevante a justificar a aplicação da lei penal ${ }^{62}$.

Neste sentido, ao se entender o direito penal como veículo de proteção exclusiva de bens jurídicos, o que se pretende, em última análise, é restringir o seu conteúdo, tratando-se, portanto, de um direito penal mínimo, e, com isso, aprimorar-lhe a efetividade no desempenho da sua função de tutela.

Ocorre que inexiste um conceito seguro, preciso e objetivado de bem jurídico, o que serve de motivo para diversas críticas acerca da inexistência de uma real função limitadora por parte da teoria, já que, a depender dos bens eventualmente selecionados para compor a esfera de proteção de uma determinada sociedade, a teoria funcionalista teleológica pode passar a funcionar, ao revés, como critério de expansão do direito penal.

\footnotetext{
${ }^{61}$ BIANCHINI, Alice; MOLINA, Antonio García-Pablos; GOMES, Luiz Flávio. Direito Penal: introdução e princípios fundamentais. 2. ed. São Paulo: Revista dos Tribunais, 2009, p. 235-236.

${ }^{62}$ ROXIN, Claus. Derecho Penal - Parte General. Tomo I. La estructura de la teoría del delito. Trad. DiegoManuel Luzon Peña; Miguel Díaz y García Conlledo; Javier de Vicente Remesal. Madrid: Civitas, 1997, p. 5253.
} 
É por esta razão que se passa a trabalhar com a Constituição como referencial axiológico para o processo de seleção desses bens que passarão a compor a esfera penal de tutela, não se chegando, todavia, a um consenso sobre esta forma de escolha - se apenas os bens expressos na Constituição poderiam ser alcançados ou se aqueles implícitos, ou mesmo não contrários ao modelo constitucional, poderiam ser agregados ao rol de tutela.

É essa a opinião de Claus Roxin, para quem a seleção de bens jurídicos deve derivar da Constituição, de modo a evitar a criminalização condicionada a concepções morais dominantes, como foi o caso da punição da homossexualidade com base em um suposto bem jurídico da "estrutura heterossexual das relações sexuais" ${ }^{63}$.

Em que pese as críticas, o funcionalismo teleológico proposto por Claus Roxin ainda é o modelo funcionalista mais amplamente aceito no Brasil, repercutindo, inclusive, em um redimensionamento da acepção de tipicidade, que passa a ser entendida não só como tipicidade formal, mas também como tipicidade material.

Desse modo, para que um fato seja considerado típico, deve haver tipicidade formal entendida como a correspondência entre a conduta praticada e os elementos objetivos e subjetivos relacionados ao tipo penal - e tipicidade material - efetiva lesão a um bem jurídico.

Esta análise valorativa deve-se, sobretudo, ao fato de o tipo penal ter o seu conteúdo desenvolvido em um campo de tensão formado entre o fim da lei e a determinação da lei, reclamando, a um só tempo, uma interpretação dogmática e valorativa, de modo que certos comportamentos legalmente desaprovados, após análise teleológica, possam ser compreendidos pelo direito ${ }^{64}$.

Para Günther Jakobs, de outro lado, se proteção a bem jurídico há, esta é apenas incidental, pois a função do direito penal jamais poderia estar edificada em uma base imprecisa e instável ${ }^{65}$. Segundo o autor, fosse a função genérica do direito penal a proteção, por exemplo, do patrimônio, teria de haver a incidência da lei penal diante de um automóvel corroído pela ferrugem, mas não é o que ocorre, precisamente porque "o direito não é um

\footnotetext{
${ }^{63}$ ROXIN, Claus. Derecho Penal - Parte General. Tomo I. La estructura de la teoría del delito. Trad. DiegoManuel Luzon Peña; Miguel Díaz y García Conlledo; Javier de Vicente Remesal. Madrid: Civitas, 1997, p. 54.

${ }^{64}$ ROXIN, Claus. Funcionalismo e imputação objetiva no direito penal. Trad. Luís Greco. Rio de Janeiro/São Paulo: Renovar, 2002, p. 234.

${ }^{65}$ CALLEGARI, André Luís; LYNETT, Eduardo Montealegre; JAKOBS, Günther; MELIÁ, Manoel Cancio. Direito penal e funcionalismo. Coord. CALLEGARI, André Luís, NEREU, José Giacomolli. Trad. André Luís Callegari, Nereu José Giacomolli e Lúcia Kalil. Porto Alegre: Livraria do Advogado, 2005, passim.
} 
muro construído para proteger os bens, é, sim, a estrutura que garante a relação entre as pessoas"66. Deste modo, sustenta o autor que a função do direito penal é a proteção de suas normas.

Além disso, o funcionalismo teleológico não seria, segundo Jakobs, um modelo teórico capaz de atender a todo e qualquer ordenamento jurídico, ao contrário de um modelo funcionalista sistêmico, a ser tratado nas seguintes linhas, capaz de ser destinado à proteção de qualquer organização normativa ${ }^{67}$.

\subsection{O Funcionalismo Sistêmico de Günther Jakobs}

Günther Jakobs utiliza como ponto de partida para o desenvolvimento do funcionalismo sistêmico ou normativista a teoria dos sistemas de Niklas Luhmann e a concepção do direito como um sistema autopoiético ${ }^{68}$. Nesse sentido, a função do direito, mais especialmente, a função do direito penal é a de proteção das suas próprias normas ${ }^{69}$.

Neste sentido, o direito penal é operacionalmente fechado, sem deixar, entretanto, de se apresentar como um sistema mutável, uma vez que as mudanças sociais que caracterizam o tempo em que se situam o sistema e o entorno, são aptas a produzir mudanças normativas e, somente assim, modifica-se uma lei penal.

Significa dizer que, antes da mencionada mudança, não é possível afastar a incidência da norma penal violada, já que o direito penal trabalha a partir da estrutura lícito/ilícito, de modo que a ocorrência da ofensa a uma norma, tenha ela atingido ou não um determinado bem jurídico, tem a força de impor a sanção penal.

Esclarece Lúcio Antônio Chamon Junior que o funcionalismo sistêmico proposto por Jakobs está pautado em uma descrição neutra do direito penal, mas se distancia, em certos

\footnotetext{
${ }^{66}$ CALLEGARI, André Luís; LYNETT, Eduardo Montealegre; JAKOBS, Günther; MELIÁ, Manoel Cancio. Direito penal e funcionalismo. Coord. CALLEGARI, André Luís, NEREU, José Giacomolli. Trad. André Luís Callegari, Nereu José Giacomolli e Lúcia Kalil. Porto Alegre: Livraria do Advogado, 2005, p. 33.

${ }^{67}$ GÜNTHER, Jakobs. Qué protege el derecho penal: bienes jurídicos o la vigencia de la norma? Mendoza: Cuyo, 2002, p. 53.

${ }^{68}$ JAKOBS, Günther. A imputação objetiva no direito penal. Trad. André Luís Callegari. São Paulo: Revista dos Tribunais, 2000, passim.

${ }^{69}$ Id. Ibid. passim.
} 
aspectos, da teoria luhmanniana, sobretudo no que diz respeito à noção de norma jurídica adotada por Jakobs e nos tipos de comunicação por este desenvolvidos ${ }^{70}$.

Segundo Chamon Junior, o funcionalismo sistêmico jurídico-penal está orientado a proteger a identidade normativa, sendo a função do direito penal a manutenção de um sistema, o que se verifica por meio da contradição a uma contradição das normas determinantes (seguindo Jakobs, nesse aspecto, o pensamento de Hegel acerca da negação da negação do direito como um processo de afirmação deste $)^{71}$.

A pena funciona, portanto, como uma confirmação ou autocomprovação da norma, promovendo, no plano comunicativo, o restabelecimento da vigência da norma jurídica violada $^{72}$. O citado restabelecimento, todavia, não é passível de comprovação empírica ${ }^{73}$.

A sanção penal, assim, corresponde à reafirmação da validade da norma violada, assumindo um caráter de prevenção geral positiva do delito perante a sociedade, supondo-se que o conhecimento da norma e de suas consequências jurídicas tem a força de produzir uma certa previsibilidade comportamental e, com isso, manter a estabilidade das relações sociais mesmo após violada uma das normas jurídicas do sistema.

O direito penal, então, assume a missão de garantia de uma identidade normativa da sociedade e, reconhecendo que a constituição da sociedade desenvolve-se por intermédio de normas, entende-se que o ataque à norma corresponde, em última análise, a um ataque a esta identidade social ${ }^{74}$.

Jakobs reconhece, todavia, a existência de defeitos volitivos capazes de produzir uma falta de fidelidade ao ordenamento jurídico, situação em que mesmo o conhecedor do sistema de normas do Estado recusa-se a reconhecê- $10^{75}$. Tal fato ocorre porque as normas sociais não são absolutas, mas débeis - e quanto mais débil é a norma, mais forte deve ser a respectiva pena, para que não se opere a morte da norma no ordenamento jurídico ${ }^{76}$.

\footnotetext{
${ }^{70}$ CHAMON JUNIOR, Lúcio Antônio. Do giro finalista ao funcionalismo penal: embates de perspectivas dogmáticas decadentes. Porto Alegre: Sergio Antônio Fabris, 2004, p. 71-72.

${ }^{71}$ Id. Ibid. p. 72.

${ }^{72}$ Id. Ibid. loc. cit.

${ }^{73}$ Id. Ibid. loc. cit.

${ }^{74}$ Id. Ibid. p. 73.

75 JAKOBS, Günther. Fundamentos do Direito Penal. Trad. André Luís Callegari. São Paulo: Revista dos Tribunais, 2003, p. 30.

${ }^{76}$ Id. Ibid. p. 31.
} 
Jakobs propõe, portanto, a aplicação da teoria do direito como um sistema autopoiético ao direito penal na justificação da incidência da lei penal diante da violação da norma, prescindindo, pois, da análise da ocorrência de efetiva lesão ou não a um determinado bem jurídico.

Não fosse assim, as normas juridicamente previstas não teriam mais a aptidão de garantir a estabilidade social, pois as condutas que se delineariam a partir de então não mais estariam fundamentadas na possibilidade de imposição da consequência jurídica, ocasionando-se a completa desordem social.

Criticando o funcionalismo normativista, Roxin discorda da concepção segundo a qual o direito não deve ceder diante do injusto, advertindo que os interesses de autoproteção não justificam o desprezo à necessidade de ponderação de bens, que está respaldada em princípios reitores do ordenamento jurídico, tais como o da proporcionalidade ${ }^{77}$.

Fábio da Silva Bozza critica a concepção de prevenção geral positiva no funcionalismo sistêmico de Jakobs, sustentando que este não explica o porquê é a pena criminal - e não meio menos violento - a forma de garantia das expectativas sociais ${ }^{78}$. Bozza ainda destaca que, observando as estatísticas criminais, a regra é a da frustração das expectativas normativas, e não o contrário, o que prova a pena não cumprir, efetivamente, uma função de prevenção geral positiva ${ }^{79}$.

Bozza ainda lança críticas à teoria sistêmica de Niklas Luhmann, atestando que o referido modelo "permite a instrumentalização do direito" ${ }^{80}$, logo "não condiz com um direito penal democrático"81.

\footnotetext{
${ }^{77}$ ROXIN, Claus. Politica criminal y sistema del derecho penal. 2. ed. Buenos Aires: Hammurabi, 2002, p. 7879.

${ }^{78}$ BOZZA, Fábio da Silva. Uma análise crítica da prevenção geral positiva no funcionalismo sistêmico de Günther Jakobs. Revista Brasileira de Ciências Criminais. São Paulo, ano 16, n. 70, janeiro-fevereiro de 2008, p. 57.

${ }^{79}$ Id. Ibid. p. 57.

${ }^{80}$ Id. Ibid. p. 59.

${ }^{81}$ Id. Ibid. loc. cit.
} 


\section{O FUNCIONALISMO SISTÊMICO E A APLICAÇÃO DA LEI PENAL}

O funcionalismo sistêmico proposto por Jakobs, dentre outras consequências, tem como impacto marcante, na aplicação da lei penal, a criação de uma nova percepção de "risco" para o direito penal, além de servir de justificativa para a aceitação dos chamados tipos penais de perigo abstrato, conforme se verá nas linhas seguintes.

\subsection{A Teoria da Imputação Objetiva e a Noção de "Risco" no Direito Penal}

Günther Jakobs desenvolve uma nova noção de "risco" para o direito penal, pautada na quebra da confiança de expectativas sociais de conduta. Nesse sentido, a quebra de confiança, seja ela intencional (dolo) ou decorra da inobservância de um dever de cuidado (culpa) justificaria a incidência da pena com o fim de prevenção geral positiva.

Segundo Juliana Cardoso Benedetti, a teoria da imputação objetiva proposta por Jakobs está fundada na "atribuição de papéis sociais, com o que se tem que só é possível responsabilizar alguém penalmente se esta pessoa atuou extrapolando os limites do seu âmbito de organização". ${ }^{82}$

Jakobs analisa os comportamentos uniformes em massa a partir da compreensão de que a sociedade moderna é uma sociedade complexa, que precisa saber administrar "comportamentos de massa distintos mas também uniformes dos cidadãos" ${ }^{83}$. A administração dos riscos está relacionada, dentre outros fatores, a um tratamento rigoroso dos indivíduos chamados "não-alinhados", conceituados como sendo aqueles que, não de maneira incidental, utilizam-se do crime como elemento comportamental ou como atividade habitual sujeitos que abandonaram o direito e, por tal razão, ameaçam a segurança social ${ }^{84}$.

Deste modo, em que pese o risco seja inerente à vida em sociedade, cabe ao Estado o gerenciamento dos riscos permitidos e dos riscos proibidos por intermédio da atuação do sistema penal.

\footnotetext{
${ }^{82}$ BENEDETTI, Juiliana Cardoso. As raízes sociológicas do funcionalismo penal: uma aproximação entre Émile Durkheim e Günther Jakobs. Revista Brasileira de Ciências Criminais. São Paulo, ano 16, n. 73, julho-agosto de 2008, p. 30.

${ }^{83}$ JAKOBS, Günther. Ciência do direito e ciência do direito penal. Trad. Maurício Antônio Ribeiro Lopes. Estudos de Direito Penal. v. 1. São Paulo: Manole, 2003, p. 44.

${ }^{84}$ Id. Ibid. p. 57.
} 
O risco permitido, segundo Jakobs, está vinculado à configuração da própria sociedade, tratando-se de uma concreção da adequação social, a exemplo da legítima defesa e do estado de necessidade ${ }^{85}$. O risco permitido, portanto, está situado nas hipóteses normais de interação dos indivíduos em sociedade ${ }^{86}$.

A distinção entre risco permitido e risco proibido, em certos casos, dependerá de um cálculo de custos e benefícios, em que "o benefício estaria constituído pela liberdade de comportamento que se obtém com a ajuda da permissão de riscos, enquanto os custos seriam a perda daqueles bens a cuja destruição conduz o risco, devendo ambos os lados manter uma relação adequada" 87 .

É o caso, por exemplo, daquele que conduz uma ambulância a uma velocidade de 75 Km por hora em uma via cuja velocidade máxima permitida é de $70 \mathrm{Km}$ por hora: viola-se uma expectativa, mas esta violação é tolerável em razão de uma análise dos custos e dos benefícios da conduta ${ }^{88}$.

O problema, todavia, está nos extremos a que a concepção funcionalista sistêmica de Jakobs pode conduzir a partir da distinção entre risco permitido e risco proibido decorrente da quebra ou não de expectativas sociais. Um exemplo claro é o do estudante de biologia que ganha um dinheiro extra trabalhando como garçom e um dos clientes solicita uma fruta exótica: o estudante, em razão de seus conhecimentos especiais em biologia, sabe que a fruta é venenosa, mas, ainda assim, serve o alimento, vindo o cliente a falecer ${ }^{89}$.

Segundo Jakobs, o estudante de biologia não poderá ser punido, pois não violou nenhum papel social, já que, no momento em que o fato ocorreu, estava atuando tão somente como garçom, tratando-se, portanto, de um risco permitido.

\footnotetext{
${ }^{85}$ JAKOBS, Günther. A imputação objetiva no direito penal. Trad. André Luís Callegari. São Paulo: Revista dos Tribunais, 2000, p. 35.

${ }^{86}$ Id. Ibid. loc. cit.

${ }^{87}$ Id. Ibid. p. 36.

${ }^{88}$ Id. Ibid. p. 39.

${ }^{89}$ Id. Ibid. p. 49.
} 


\subsection{Os Tipos Penais de Perigo Abstrato e a Proteção da Norma Penal}

Os tipos de perigo abstrato são aqueles em que a incidência da lei penal prescinde da ocorrência de um dano material efetivo, ou mesmo de um perigo concreto de dano a um determinado bem jurídico.

Em tais espécies delitivas, o risco criado está não na conduta em si, mas presumido no próprio tipo incriminador, de modo que a simples prática da conduta prevista em lei como crime justifica, por si só, a aplicação da pena.

Tome-se, como exemplo na legislação brasileira, o porte ilegal de arma desmuniciada, delito previsto no art. 14, caput, da Lei n. 10.826/2003, situação em que o Superior Tribunal de Justiça tem se pronunciado, reiteradamente, pela dispensabilidade do laudo pericial destinado a aferir a potencialidade lesiva do objeto material do crime, por se tratar de tipo penal de perigo abstrato ${ }^{90}$.

É o caso, também, do crime de embriaguez ao volante, art. 306 da Lei n. 9.503/97, que, após a alteração promovida pela Lei n. 11.705/08 objetivou o conceito legal de embriaguez definindo a concentração de álcool a partir da qual se impõe a incidência do tipo incriminador, quantidade esta hoje regulada por meio da Lei n. 12.760, de 2012, que disciplina ser criminosa a condução do veículo sob concentração igual ou superior a 6 decigramas de álcool por litro de sangue ou igual ou superior a 0,3 miligrama de álcool por litro de ar alveolar. Neste sentido, o Supremo Tribunal Federal manifestou-se pela desnecessidade de comprovação, para além da já referida concentração, de perda de capacidade motora por parte do motorista ${ }^{91}$.

Segundo Jakobs, os tipos penais de perigo abstrato são necessários ao controle social, uma vez que determinadas modalidades de comportamento, aparentemente inócuas, podem se apresentar como perigosas ${ }^{92}$. Resta saber, conforme esclarece o autor, se há fundamentos suficientes para tratar tais condutas não como mera infração contra a ordem pública, mas sim como delito criminal ${ }^{93}$.

\footnotetext{
${ }^{90}$ STJ, EDcl no AgRg no AREsp 130342 / SC, 5 a Turma, DJe 22/03/2013.

${ }^{91} \mathrm{STF}, \mathrm{RHC} 110258$ / DF, 1a Turma, PUBLIC 24-05-2012.

92 JAKOBS, Gunther. Sociedade, norma e pessoa: teoria de um direito penal funcional. Trad. Maurício Antônio Ribeiro Lopes. Estudos de Direito Penal. v. 6. São Paulo: Manole, 2003, p. 24-25.

${ }^{93}$ Id. Ibid. p. 25.
} 
Outro argumento apresentado pelo autor é o fato de a segurança se apresentar não como um mero reflexo da atividade policial, mas como um direito essencial de cada indivíduo, de modo que os delitos de perigo abstrato "não apenas perturbam a ordem pública, mas lesionam um direito à segurança" - segurança esta entendida no sentido normativo ${ }^{94}$.

\section{CONSIDERAÇÕES FINAIS}

A partir do conceito de sistema jurídico autopoiético apresentado no primeiro tópico, bem como de suas críticas, bem como das duas correntes funcionalistas antagônicas, teleológica e normativista, é possível tecer as seguintes considerações críticas a respeito da aplicação do modelo autopoiético de direito aplicado ao direito penal:

A. O direito, especialmente em sistemas jurídicos "periféricos", não pode ser estudado sob uma perspectiva autopoiética, uma vez que a política e a economia correspondem a fatores reais capazes de subverter a ordem jurídica e de conformar as estruturas do ordenamento jurídico, de modo que seu sistema organizacional passa a operar de modo meramente simbólico, sem garantir a estabilidade, auto-organização e autonomia esperadas de um sistema autopoiético.

B. O direito, concretamente, assume a forma de um sistema alopoiético, uma vez que sua abertura cognitiva não está atrelada a um fechamento operacional capaz de conter a força condicionante desempenhada por interesses de ordem privada.

C. Reconhecendo-se o direito como sistema condicionado por interesses políticos e econômicos, cabe ao direito penal desempenhar uma função de garantia, restringindo o seu âmbito de incidência e questionando, criticamente, a imposição da sanção penal.

D. Cumpre questionar o conteúdo das estruturas sistemáticas, não sendo a produção de leis conforme os critérios predefinidos de reconstrução suficientes para lhes justificar a incidência, somente se legitimando a aplicação de uma sanção criminal caso tenha

\footnotetext{
${ }^{94}$ JAKOBS, Gunther. Sociedade, norma e pessoa: teoria de um direito penal funcional. Trad. Maurício Antônio Ribeiro Lopes. Estudos de Direito Penal. v. 6. São Paulo: Manole, 2003, p. 26-27.
} 
havido, para além da ofensa à norma, uma lesão ou perigo concreto de lesão a um bem jurídico.

E. A teoria do bem jurídico, em que pese não seja passível de uma objetivação absoluta quanto ao seu conteúdo, não deve ser abandonada enquanto modelo reitor do direito penal, uma vez que funciona como um princípio limitador do âmbito de incidência da lei penal.

F. A noção de risco proibido deve ser construída tendo como base a ofensa a um bem jurídico relevante, e não a quebra de confiança decorrente da frustração de uma expectativa generalizada de comportamento.

G. Não se pode admitir a aplicação de sanção criminal a condutas em que não se comprove, ao menos, a ocorrência de um risco concreto para o ordenamento jurídico, não podendo a acusação se desincumbir do ônus de provar a lesividade - concreta ou potencial da conduta, de modo que condutas como porte ilegal de arma ou embriaguez ao volante persistem como figuras puníveis, mas desde que o sujeito ativo tenha apresentado, pelo menos, um risco concreto ao bem juridicamente tutelado.

\section{REFERÊNCIAS}

BIANCHINI, Alice; MOLINA, Antonio García-Pablos; GOMES, Luiz Flávio. Direito Penal: introdução e princípios fundamentais. 2. ed. São Paulo: Revista dos Tribunais, 2009.

BENEDETTI, Juiliana Cardoso. As raízes sociológicas do funcionalismo penal: uma aproximação entre Émile Durkheim e Günther Jakobs. Revista Brasileira de Ciências Criminais. São Paulo, ano 16, n. 73, julho-agosto de 2008.

BOZZA, Fábio da Silva. Uma análise crítica da prevenção geral positiva no funcionalismo sistêmico de Günther Jakobs. Revista Brasileira de Ciências Criminais. São Paulo, ano 16, n. 70, janeiro-fevereiro de 2008, p. 41-70.

CALLEGARI, André Luís; LYNETT, Eduardo Montealegre; JAKOBS, Günther; MELIÁ, Manoel Cancio. Direito penal e funcionalismo. Coord. CALLEGARI, André Luís, NEREU, José Giacomolli. Trad. André Luís Callegari, Nereu José Giacomolli e Lúcia Kalil. Porto Alegre: Livraria do Advogado, 2005. 
CHAMON JUNIOR, Lúcio Antônio. Do giro finalista ao funcionalismo penal: embates de perspectivas dogmáticas decadentes. Porto Alegre: Sergio Antônio Fabris, 2004.

GRECO, Luís. A teoria da imputação objetiva: uma introdução. In: ROXIN, Claus. Funcionalismo e imputação objetiva no direito penal. Trad. Luís Greco. Rio de Janeiro/ São Paulo: Renovar, 2002.

GÜNTHER, Jakobs. Ciência do direito e ciência do direito penal. Trad. Maurício Antônio Ribeiro Lopes. Estudos de Direito Penal. v. 1. São Paulo: Manole, 2003.

. Sociedade, norma e pessoa: teoria de um direito penal funcional. Trad. Maurício Antônio Ribeiro Lopes. Estudos de Direito Penal. v. 6. São Paulo: Manole, 2003.

O direito de resistência: à legítima defesa, ao estado de necessidade e ao consentimento. In: FÖPPEL, Gamil (Org.). Novos desafios do direito penal no terceiro milênio: estudos em homenagem ao prof. Fernando Santana.Rio de Janeiro: Lumen Juris, 2008.

. A imputação objetiva no direito penal. Trad. André Luís Callegari. São Paulo: Revista dos Tribunais, 2000.

Qué protege el derecho penal: bienes jurídicos o la vigencia de la norma? Mendoza: Cuyo, 2002.

Fundamentos do Direito Penal. Trad. André Luís Callegari. São Paulo:

Revista dos Tribunais, 2003.

HASSEMER, Winfried. Perspectivas de uma moderna política criminal. Revista Brasileira de Ciências Criminais. São Paulo, n. 8, out-dez, 1994, p. 41-51.

HESPANHA, Benedito. A autopoiese na construção do jurídico e do político de um sistema constitucional. Revista dos Tribunais - Cadernos de Direito constitucional e Ciência Política. São Paulo, Ano 7, n. 27, abril-junho de 1999, p. 59-78.

LUHMANN, Niklas. Sociologia do Direito I. Coleção dirigida por Eduardo Portella. Trad. Gustavo Bayer. Série Biblioteca Tempo Universitário n $75 /$ Série Estudos Alemães. Rio de Janeiro: Tempo Brasileiro, 1983. 
Sociologia do Direito II. Coleção dirigida por Eduardo Portella. Trad. Gustavo Bayer. Série Biblioteca Tempo Universitário n $75 /$ Série Estudos Alemães. Rio de Janeiro: Tempo Brasileiro, 1985.

La sociedad de la sociedad. México: Universidad Iberoamericana Biblioteca Francisco Xavier Clavigero, 2006.

El Derecho de la Sociedad. Formatação eletrônica de João Protásio Farias

Domingues de Vargas, Marjorie Corrêa Marona e Juliana Neuenschwander Magalhaes. Brasil, 2002.

NEVES, Marcelo. Luhmann, Habermas e o estado de direito. Lua Nova: Revista de Cultura e Política, n. 37, São Paulo, 1996. Disponível em: < http://www.scielo.br/scielo.php?pid=S0102-64451996000100006\&script=sci_arttext >. Acesso em: 03 de abril de 2013.

ROCHA, Leonel Severo; SCHWARTZ, Germano; CLAM, Jean. Introdução à teoria do sistema autopoiético de direito. Porto Alegre: Livraria do Advogado, 2005.

ROXIN, Claus. Funcionalismo e imputação objetiva no direito penal. Trad. Luís Greco. Rio de Janeiro/São Paulo: Renovar, 2002.

Politica criminal y sistema del derecho penal. 2. ed. Buenos Aires:

Hammurabi, 2002.

. Derecho Penal - Parte General. Tomo I. La estructura de la teoría del delito. Trad. Diego-Manuel Luzon Peña; Miguel Díaz y García Conlledo; Javier de Vicente Remesal. Madrid: Civitas, 1997.

SCALCON, Rachel Lima. Funcionalismo penal da Escola de Munique: contributos e inconsistências de uma construção do conceito de crime a partir dos fins de política criminal. Revista Síntese Direito Penal e Direito Processual Penal. Continuação da Revista IOB de Direito Penal e Processual Penal. Porto Alegre, v.1, n.1, abr./maio, 2000, p. 72-93.

SCHWARTZ, Germano. Autopoiese e constituição: os limites da hierarquia e as possibilidades da circularidade. Revista Brasileira de Direito Constitucional (RBDC): Revista do Programa de Pós-Graduação Lato Sensu em Direito Constitucional. Escola Superior de Direito Constitucional (ESDC). São Paulo, n.6, 2005, p. 211-224. 
ZAFFARONI, Eugenio Raul; ALAGIA, Alejandro; SLOKAR, Alejandro. Derecho penal: parte general. Buenos Aires: Ediar, 2001.

Submissão: $15 / 10 / 2013$

Aceito para Publicação: 28/12/2013 